\title{
Study of the influence of compressive force on the coefficients of friction for wool-containing fabrics
}

\author{
Raya Stoyanova ${ }^{1 *}$, Sasho Aleksandrov², and Umme Kapanak ${ }^{3}$ \\ ${ }^{1}$ Southwestern University "Neofit Rilski" - Blagoevgrad, Department of Mechanical Engineering and \\ Technology, Bulgaria, email: raikach@abv.bg \\ ${ }^{2}$ Technical University - Gabrovo, Department of Textile Engineering and Technology; Bulgaria, \\ email: sasho49@abv.bg \\ ${ }^{3}$ Southwestern University "Neofit Rilski" - Blagoevgrad, Department of Mechanical Engineering and \\ Technology, Bulgaria, email: $\underline{\text { umi12@abv.bg }}$
}

\begin{abstract}
Making use of appliance MXD-02, Labthink, China, coefficient of friction at rest with sliding tendency (static coefficient of friction) and coefficient of friction at sliding (dynamic coefficient of friction) for fabrics made of $100 \%$ wool as well as woolen fabrics with admixtures of polyamide and polyester were determined. The influence of the magnitude of normal pressure on the coefficients of friction was studied. Experiments taking into consideration the following different directions of relative fabric movement were performed: warp by warp threads, and warp by weft. An analysis of the obtained results was made.
\end{abstract}

\section{Introduction}

The present study is part of a larger scientific study related to the determination of the friction coefficients of woven textiles made of natural fibers - cotton, silk and wool. The aim of the study is to experimentally determine the friction coefficients of weaved products containing wool.

In Bulgaria, production of fabrics, especially those made of wool, is greatly underdeveloped. The main producer of woolen fabrics in Bulgaria is the Miroglio factory Sliven. At the time this experimental research, the plant in Sliven produces four items with wool content. The studied fabrics have different characteristics - weaves, surface weight, density and composition of the fabric.

Pure friction is described by Amonton's law, according to which the friction force $T$ is proportional to the normal pressure $N$, and the coefficient of proportionality $\mu$ is called the coefficient of friction:

$$
T=\mu . N .
$$

As evidenced by formula (1), friction force does not depend on the size of the contact area between the friction surfaces, it is only dependent on the normal pressure and the friction coefficient.

\footnotetext{
* Corresponding author: raikach@abv.bg
} 
In textile materials, friction is accompanied by the occurrence of adhesion forces $\mathrm{A}$, in which the coefficient of friction is expressed by Amonton-Coulomb's model:

$$
\mu=\frac{\mathrm{T}}{N+A} \text {. }
$$

With significant adhesion forces, the coefficient can take values above 1 .

Additionally, electrostatic forces are also observed in the relative friction of woolcontaining fabrics.

Coefficient of friction $\mu$ is static $\mu_{s t}$ (at rest with sliding tendency) and dynamic $\mu_{d y n}$ (at relative motion of the two surfaces at friction).

The study of coefficients of friction for the textile industry is essential for cases such as: layering of fabrics, cutting of multilayer textiles and their subsequent separation, packaging and storage of fabrics and ready-made items, etc.

A number of authors $[1,2,6]$, including the current team of authors [8-10], have studied the coefficients of friction of different fabrics, differing in composition, structure, finishing, etc.

Due to the small volume of wool fabric production in Bulgaria compared to countries of the European Union and worldwide (compared to other fabrics such as cotton, polyester, viscose, etc.), the literature lacks current or complete data on their friction coefficients.

Therefore, the aim of the presented study is to determine the static and dynamic coefficients of friction of fabrics made of $100 \%$ wool and woolen fabrics mixed with synthetic fibers, examining the influence of compressive force and the direction of friction of surfaces.

\section{Used materials}

To fit the study's purposes, four different fabrics with wool content, produced by the company "Miroglio", Sliven, Bulgaria, were selected. The fabrics have different structures as shown on Fig. 1.

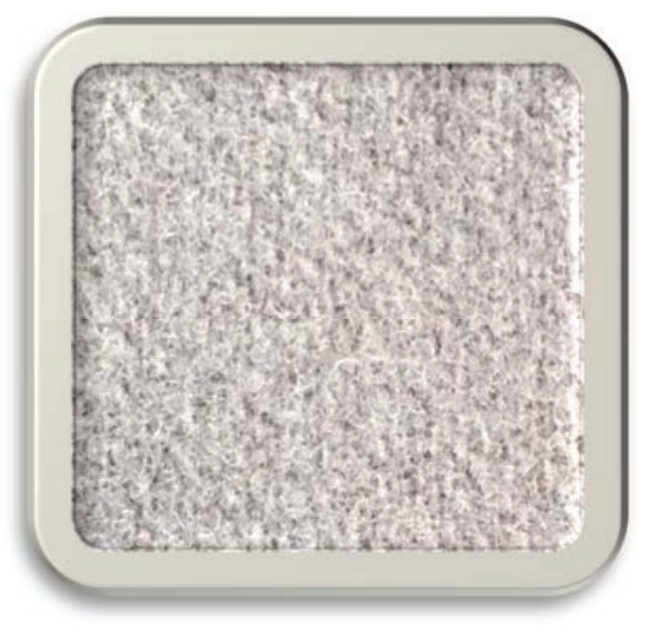

a) Delia

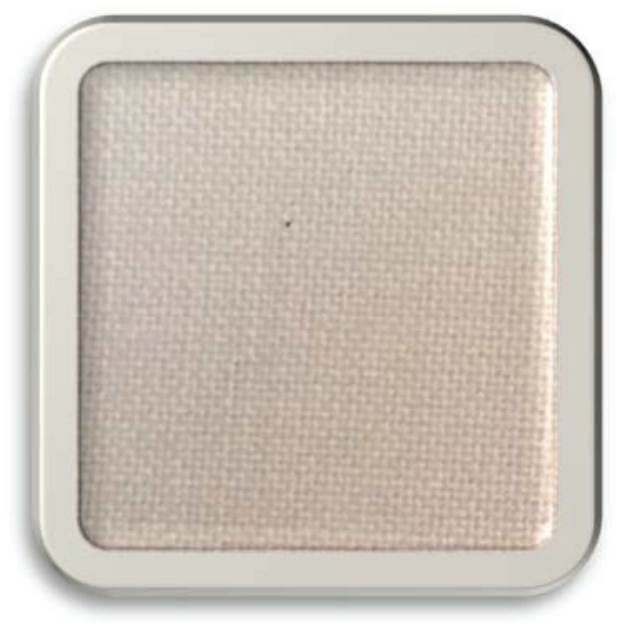

b) Miss 


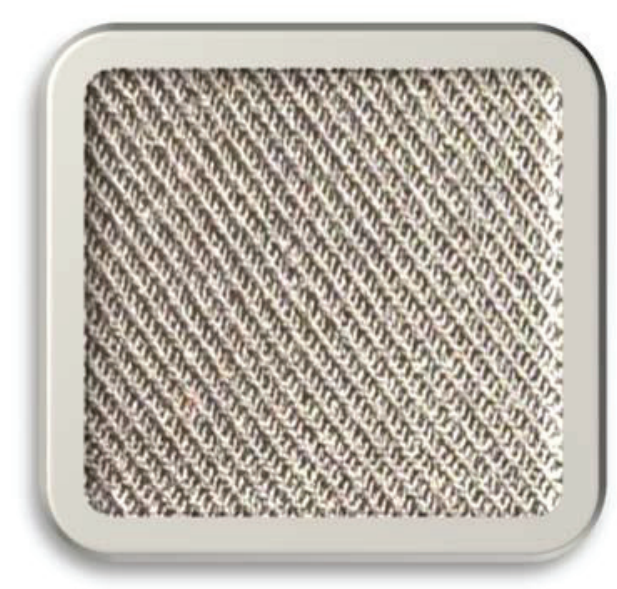

c) Rexos

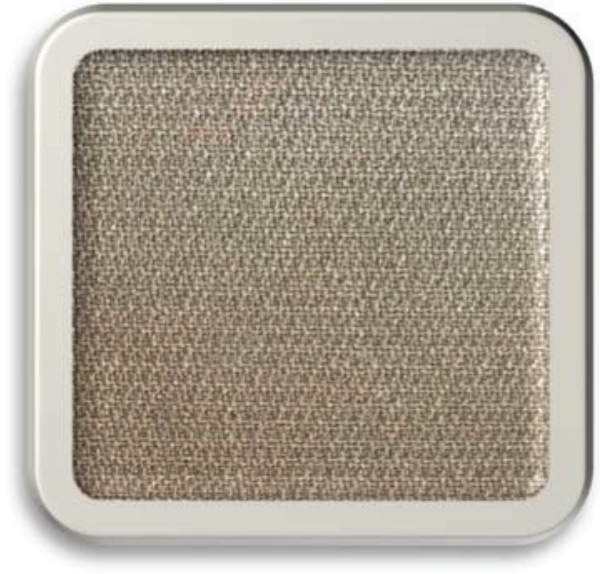

d) Oreste

Fig.1. Structure of studied fabrics

The characteristics of these fabrics are presented in Table. 1.

Table 1. Characteristics of the studied wool fabrics

\begin{tabular}{|c|c|c|c|c|c|c|c|c|c|}
\hline \multirow[t]{2}{*}{ № } & \multirow[t]{2}{*}{ Item } & \multirow[t]{2}{*}{ Weave } & \multirow{2}{*}{$\begin{array}{c}\text { Surface } \\
\text { area, } \\
\text { g/m } \mathbf{m}^{2}\end{array}$} & \multicolumn{2}{|c|}{$\begin{array}{c}\text { Linear density, } \\
\text { tex }\end{array}$} & \multicolumn{2}{|c|}{\begin{tabular}{|c|} 
Density, \\
thread number/dm \\
\end{tabular}} & \multirow[t]{2}{*}{ Composition } & \multirow{2}{*}{$\begin{array}{c}\begin{array}{c}\text { Fabric } \\
\text { width }\end{array} \\
\mathrm{cm} \\
\end{array}$} \\
\hline & & & & Warp & Weft & Warp & Weft & & \\
\hline 1 & Delia & Sn1/4Z & 380 & 105 & 105 & 171 & 160 & $\begin{array}{c}\text { PA/ VirginWool } \\
20 \% / 80 \%\end{array}$ & $150 / 145$ \\
\hline 2 & Miss & $\begin{array}{l}\text { reps } \\
\text { trame: } \\
2-2\end{array}$ & 153 & $16,7 \times 2$ & $29,4 \times 1$ & 236 & 215 & $\begin{array}{c}\text { PE/VirginWool } \\
/ \mathrm{E} \\
54 \% / 44 \% / 2 \%\end{array}$ & $150 / 145$ \\
\hline 3 & Rexos & $\mathrm{Se} 2 / 2 \mathrm{Z}$ & 196 & $16,7 \times 2$ & $16,7 \times 2$ & 275 & 270 & $\begin{array}{c}\text { PE/VirginWool } \\
55 \% / 45 \%\end{array}$ & $153 / 148$ \\
\hline 4 & Oreste & $\begin{array}{c}\text { reps } \\
\text { trame: } \\
2-2-1-1\end{array}$ & 190 & $21 \times 2$ & $25 \times 1$ & 266 & 265 & $\begin{array}{c}\text { VirginWool } \\
100\end{array}$ & $151 / 153$ \\
\hline
\end{tabular}

Note: PA - polyamide, PE-polyester, E-elastane

\section{Test methodology and experimental part}

Appliance MXD-02, Company Labthink, China is used to determine the coefficients of friction (Fig. 2).

The tester allows work according to different standards, as the tests are conducted according to BDS EN ISO 8295: 2006. The friction is performed fabric in fabric, the block has a mass of $200 \mathrm{~g}$, and the sliding speed $-100 \mathrm{~mm} / \mathrm{min}$.

Additional weights are placed on the block to determine the effect of the compressive force on the coefficients of friction. Measurements were made under pressure of $200 \mathrm{~g}$ (without additional weight), $300 \mathrm{~g}$ and $400 \mathrm{~g}$. Change in load is done by placing additional weights on the sled. The results as well as the statistical error are displayed on the tester screen during each test. 
Two samples are prepared for each test. One sample measures $80 \times 200 \mathrm{~mm}$. It is cut with the long side in the direction of the warp threads. It is placed face up on the movable plate 2 and is fastened by means of the clamping terminal 5. The second sample is cut with dimensions $120 \times 120 \mathrm{~mm}$. It is attached by means of springs to the sliding block 4 with the front side outwards. Two measurements are made: in the first case, the sample is placed so that the friction is carried out in the direction of the warp threads, and in the second - in the direction of the weft threads.

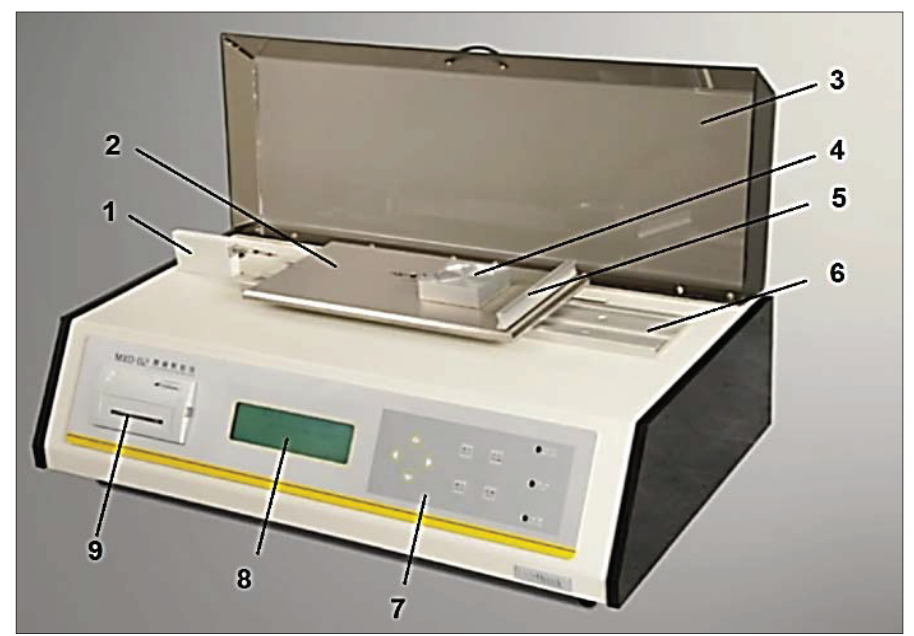

1. Force measuring sensor 2. Movable plate; 3. Lid; 4. Sliding block; 5. Clamping terminal; 6. Guide rail; 7. Control panel; 8. LCD display; 9. Microprinter

Fig. 2. Overall appearance of appliance MXD-02

Fig. 3 shows a typical friction curve. It indicates the static friction force and the sliding friction force. Static friction force and sliding friction force are needed to determine the static coefficient of friction and the coefficient of friction during sliding.

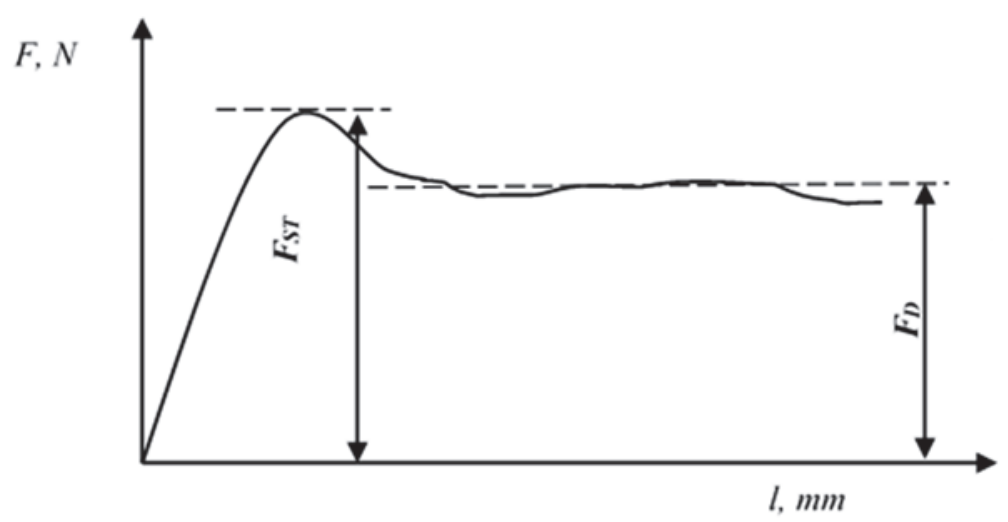

Fig. 3. Friction curve 
Static coefficient is determined by the force read in the 16th second from the beginning of the test, because at that moment the metal thread connecting the force measuring sensor and the block straightens and starts sliding the block. Dynamic coefficient is determined by the average value of the measured friction forces after the 16th second (Fig. 4).

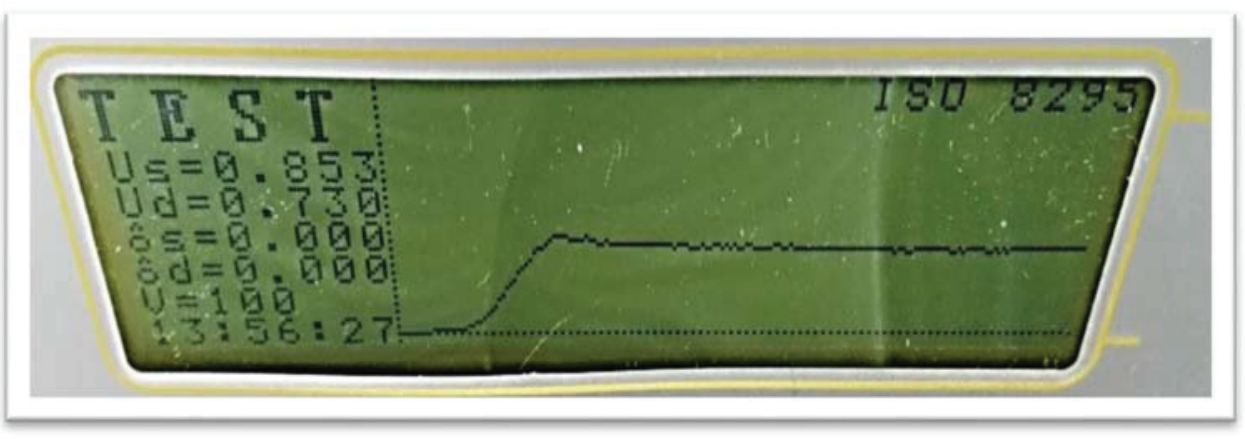

Fig. 4 Change in friction force over time

Three tests were performed for each material, the average result values of which are presented in Table 2.

Table 2. Values of coefficients of friction at rest and at sliding

\begin{tabular}{|c|c|c|c|c|c|}
\hline \multirow{2}{*}{$\stackrel{\Xi}{\Xi}$} & \multirow{2}{*}{$\frac{\text { Load }}{\mathrm{g}}$} & \multicolumn{2}{|c|}{ Static coefficient of friction } & \multicolumn{2}{|c|}{ Dynamic coefficient of friction } \\
\hline & & $\begin{array}{l}\text { Warp FS- } \\
\text { Warp FS* }\end{array}$ & $\begin{array}{l}\text { Warp FS - } \\
\text { Weft FS** }\end{array}$ & $\begin{array}{l}\text { Warp FS- } \\
\text { Warp FS }\end{array}$ & $\begin{array}{c}\text { Warp FS - } \\
\text { Weft FS }\end{array}$ \\
\hline \multirow{3}{*}{ 䋨 } & 200 & 1,1636 & 1,1493 & 1,0776 & 1,0666 \\
\hline & 300 & 1,2856 & 1,4866 & 1,4726 & 1,4926 \\
\hline & 400 & 1,6936 & 1,6970 & 1,8440 & 1,8566 \\
\hline \multirow{3}{*}{$\stackrel{\mathscr{a}}{\grave{z}}$} & 200 & 0,5903 & 0,6343 & 0,4893 & 0,5470 \\
\hline & 300 & 0,8276 & 0,8850 & 0,6643 & 0,7546 \\
\hline & 400 & 0,9663 & 1,1113 & 0,8136 & 0,9660 \\
\hline \multirow{3}{*}{$\begin{array}{l}\tilde{0} \\
\ddot{0}\end{array}$} & 200 & 0,6716 & 0,5960 & 0,5263 & 0.5050 \\
\hline & 300 & 0,8760 & 0,8360 & 0,7123 & 0,6903 \\
\hline & 400 & 1,0720 & 1,0603 & 0,8840 & 0,8500 \\
\hline \multirow{3}{*}{$\begin{array}{l}0 \\
\frac{\Delta}{0} \\
0 \\
0\end{array}$} & 200 & 1,0103 & 0,9240 & 0,9313 & 0,8506 \\
\hline & 300 & 1,3683 & 1,2246 & 1,2636 & 1,1350 \\
\hline & 400 & 1,4966 & 1,4866 & 1,5873 & 1,3820 \\
\hline
\end{tabular}

Note: Warp FS*-Warp; Weft FS**-weft.

All results are graphically presented in Fig. 5-12. 


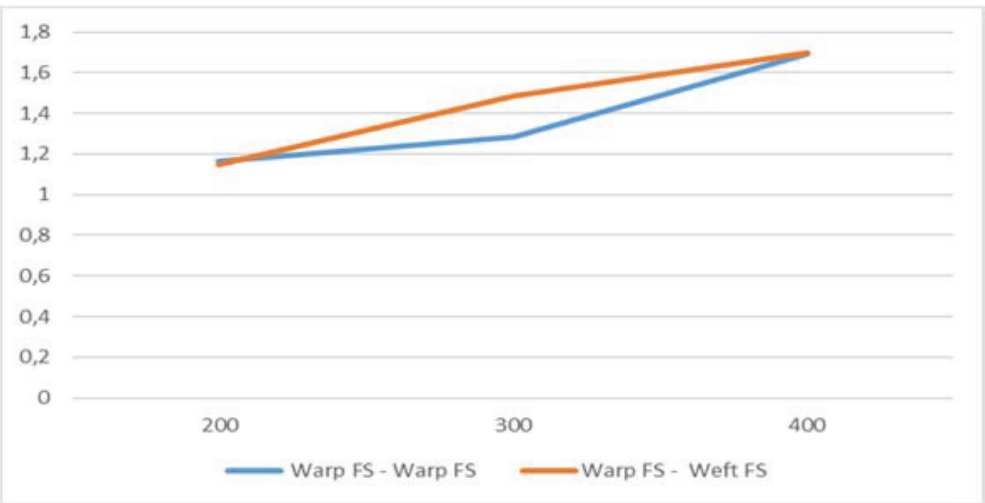

Fig.5. Static coefficient of friction for item Delia

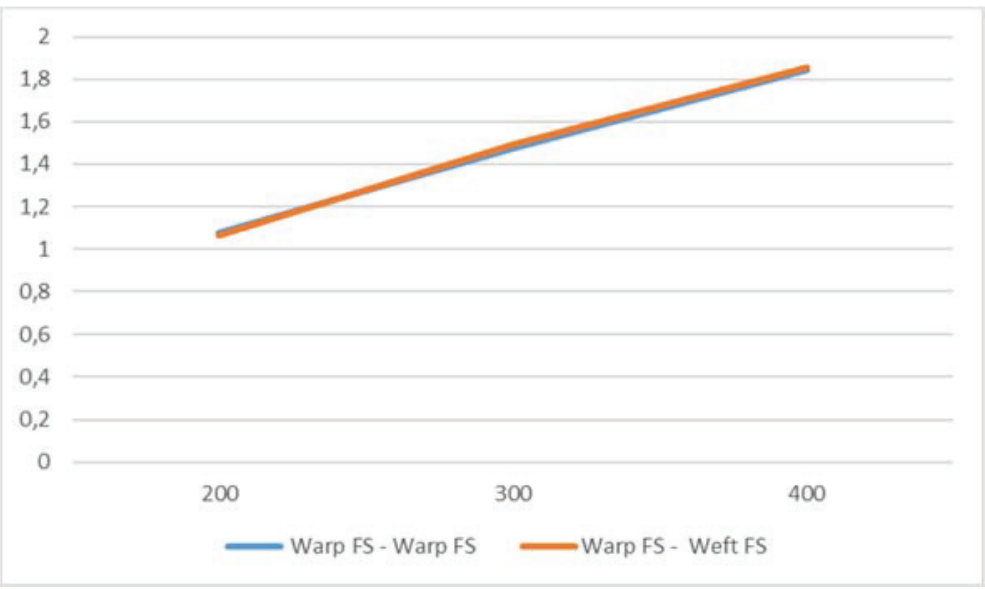

Fig 6. Sliding coefficient of friction for item Delia

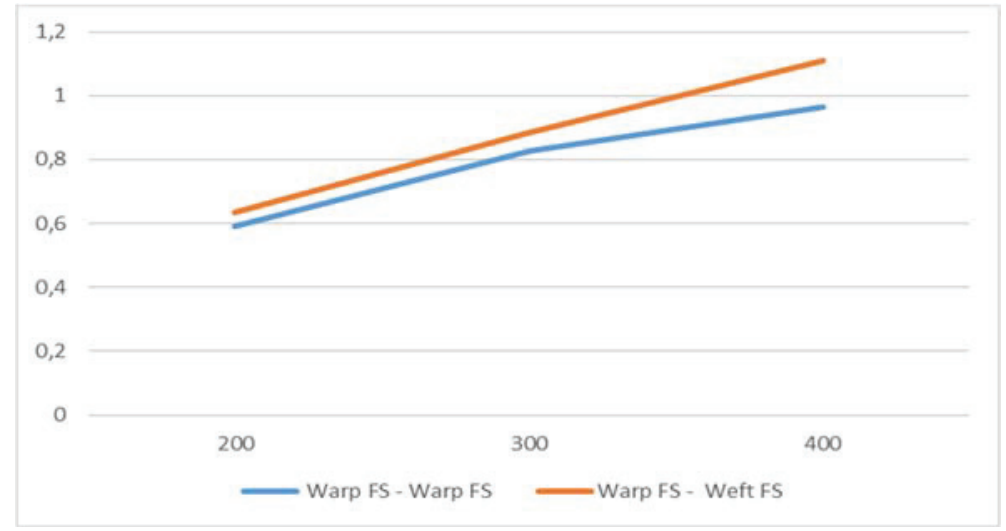

Fig. 7. Static coefficient of friction for item Miss 


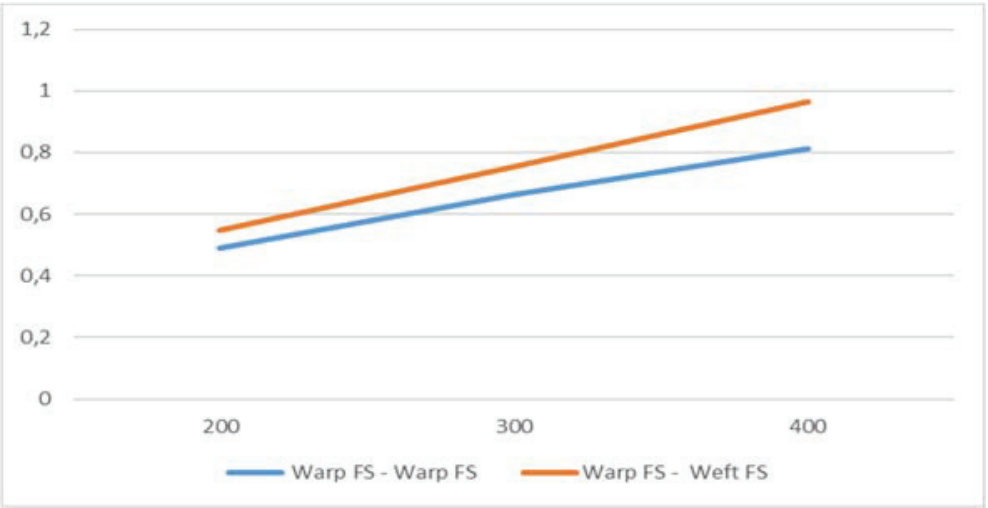

Fig. 8. Sliding coefficient of friction for item Miss

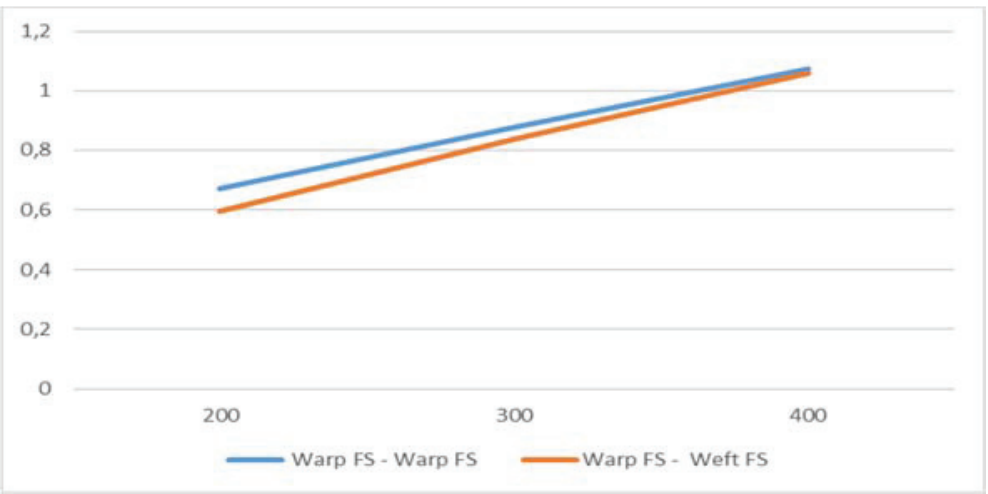

Fig. 9. Static coefficient of friction for item Rexos

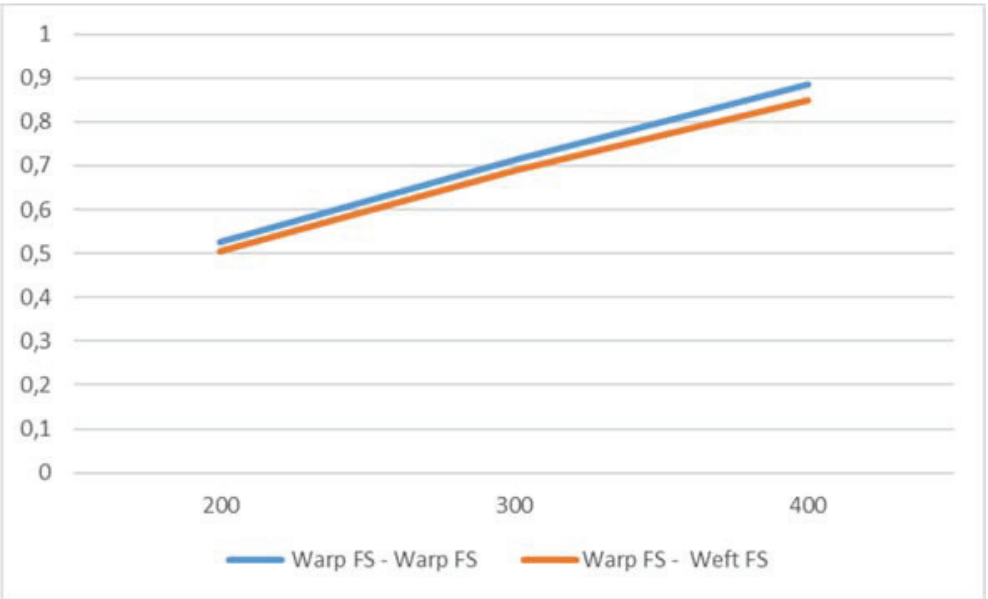

Fig. 10. Sliding coefficient of friction for item Rexos 


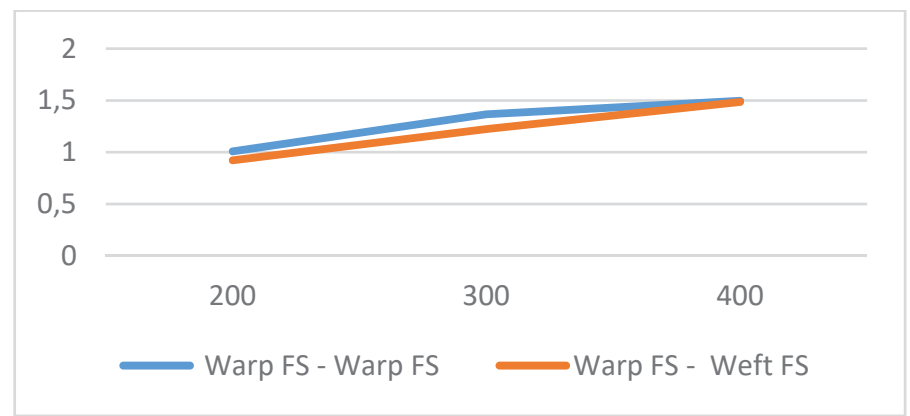

Fig. 11 Static coefficient of friction for item Oreste

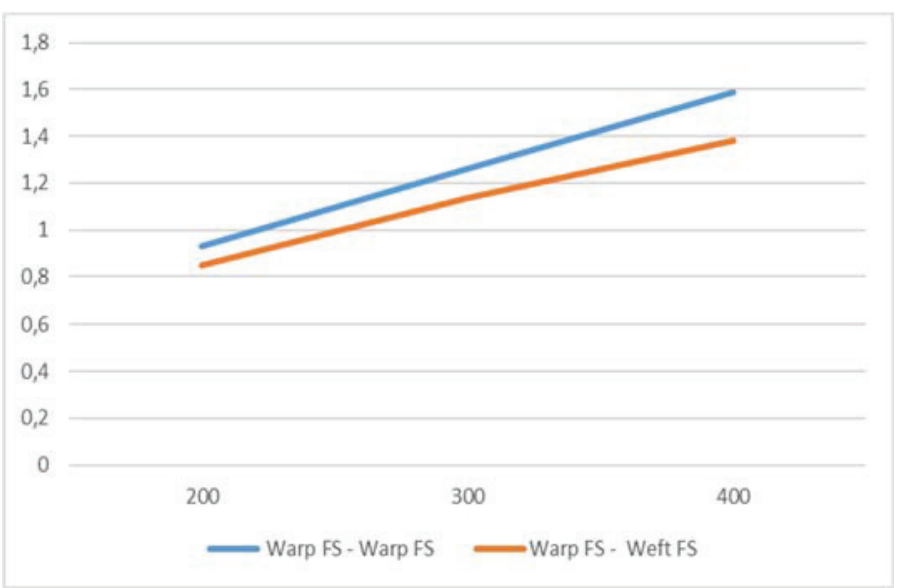

Fig. 12 Sliding coefficient of friction for item Oreste

\section{Analysis and conclusions}

As a result of the study, the following conclusions can be drawn:

- Coefficients of friction at rest for wool and wool-containing fabrics are determined, and depending on the fabric composition and direction of friction they vary in the range from 0.48 to 1.86 .

- Higher coefficients of friction are observed for item Delia, which has $20 \%$ polyamide content and $80 \%$ wool content. It is close in composition to $100 \%$ woolen fabrics; the presence of polyamide fibers provides volume and increased resistance.

- Regarding the arrangement of the threads for Delia, Miss and Rexos items (woolen fabrics with admixture of polyamide and polyester), the friction forces are higher when the warp threads of one fabric are parallel to the weft threads of the other fabric. This result is expected and confirmed by other studies [10]. For item Oreste, the friction forces are greater when the two layers of fabric are placed in parallel.

- Coefficients of friction during movement (sliding) are logically lower than those at rest with tendency to slide.

- Compressive force influences the coefficients of friction: According to Amonton's law, if the textile material were a solid body, the frictional force applied to it would be proportional to the normal compressive force. Big surface area textile products are voluminous and relatively easily deformable, which explains the change in friction coefficient as compressive force is applied. As the compressive force increases, the 
structure of the material thickens and the coefficients of friction increase. The dynamic coefficient changes the most in fabrics made of $100 \%$ wool (Oreste) and fabric containing $80 \%$ wool and $20 \%$ polyacrylic (Delia). These two items have similar surface areas, respectively for Delia - $270 \mathrm{~g} / \mathrm{m} 2$, and for Oreste - $290 \mathrm{~g} / \mathrm{m} 2$.

- Two of the items - Miss and Rexos have similar wool and polyester content, but different weave. Item Miss has higher static and dynamic coefficient of friction in direction warp front - weft front side. In Rexos, the opposite is observed - the values of the dynamic and static coefficient are higher in the direction warp face - warp face.

\section{Conclusion}

New data has been obtained for the static and dynamic coefficients of friction of wool and wool fabrics with admixture of polyamide and polyester. Trends for the influence of the direction of friction, established for fabrics with other structures and composition, have been confirmed. It was found that the studied woolen fabrics increase their coefficient of friction in proportion to normal compressive force. The increase is more pronounced in bulkier materials and with a higher wool content.

\section{References}

1. Bhuvana D. et al. Studies on Frictional Behaviour of Chitosancoated Fabrics, Autex Research Journal, vol. 6, no. 4, December 2006, pp. 216-222. (2006)

2. Das A., V. K. Kothari, N. Vandana. A Study on Frictional Characteristics of Woven Fabrics, AUTEX Research Journal, Vol. 5, No3, September 2005, AUTEX, p. 135. (2005)

3. Hermann D. B. Mathematical Characterization of Frictional Properties, A Thesis in Mathematics, Texas Tech University, (2003)

4. Hirani, H., Fundamentals of Engineering Tribology with Applications, 1st Edition, Kindle Edition, (2016).

5. Leach, S. Coefficient of Static Friction: A Simple Experiment for Applied Mechanics Students. Proceedings of the National Educators' Workshop: Update 2004, Phoenix, AZ, (2004)

6. Sülar V. Et al. Roughness and Frictional Properties of Cotton and Polyester Woven Fabrics. Indian Journal of Fiber End Textile Research, vol. 38. December 2013, pp. 349356. (2013)

7. Wilson D. Study of Fabric-on-Fabric Dynamic Friction, Journal of Textile Institute \& Industry, April 1963, Vol. 1, Iss. 4, p. 2. (1963)

8. Alexandrov S., D. Germanova-Krasteva. Study of the influence of the type of fabric softener on the coefficients of friction of towels, XVIII Scientific Conference with international participation EMF 2013, Sozopol, 15.09-18.09.2013, Proceedings, Volume II, pp. 161-165. (2013)

9. Germanova-Krasteva D., Alexandrov S. Influence of the force of pressure on the frictional characteristics of towels, XVIII Scientific Conference with international participation EMF 2013, Sozopol, 15.09-18.09.2013, Proceedings, Volume II, p. 183191. (2013);

10. Chingova R., Germanova-Krasteva D. Experimental study of the frictional characteristics of cotton fabrics with twill 3/1, Mechanics of Machines, Book 1, 2019, ISSN 0861-9727, pp. 27-31. (2019) 